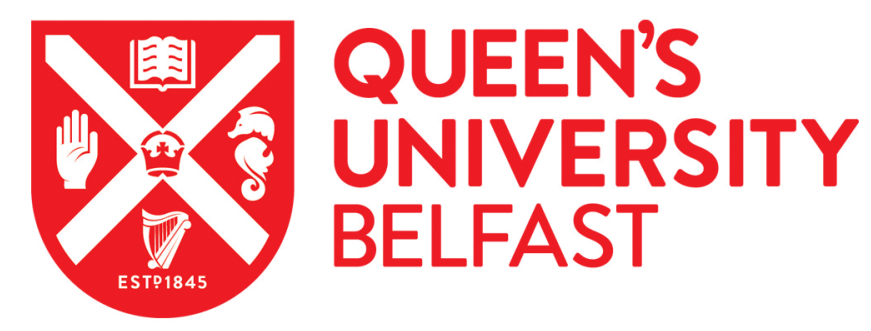

\title{
Steering towards collaborative assessment: a qualitative study of parents' experiences of evidence-based assessment practices for their child with cerebral palsy
}

O'Connor, B., Kerr, C., Shields, N., Adair, B., \& Imms, C. (2019). Steering towards collaborative assessment: a qualitative study of parents' experiences of evidence-based assessment practices for their child with cerebral palsy. Disability and Rehabilitation. https://doi.org/10.1080/09638288.2019.1629652

Published in:

Disability and Rehabilitation

Document Version:

Peer reviewed version

Queen's University Belfast - Research Portal:

Link to publication record in Queen's University Belfast Research Portal

Publisher rights

(c) 2019 Taylor \& Francis. This work is made available online in accordance with the publisher's policies. Please refer to any applicable terms of use of the publisher.

\section{General rights}

Copyright for the publications made accessible via the Queen's University Belfast Research Portal is retained by the author(s) and / or other copyright owners and it is a condition of accessing these publications that users recognise and abide by the legal requirements associated with these rights.

Take down policy

The Research Portal is Queen's institutional repository that provides access to Queen's research output. Every effort has been made to ensure that content in the Research Portal does not infringe any person's rights, or applicable UK laws. If you discover content in the

Research Portal that you believe breaches copyright or violates any law, please contact openaccess@qub.ac.uk. 


\section{Manuscript Title}

Steering towards collaborative assessment: A qualitative study of parents' experiences of evidence-based assessment practices for their child with cerebral palsy.

\section{Running Head}

Parent experience of assessment in $\mathrm{CP}$

\section{Article category}

Research Paper

Authors

Bridget O’Connor1, Claire Kerr2,1, Nora Shields3, Brooke Adair4, Christine Imms4

\section{Affiliations}

1. School of Allied Health, Australian Catholic University, Melbourne, Australia

2. School of Nursing and Midwifery, Queen's University Belfast, Belfast, UK

3. School of Allied Health, La Trobe University, Melbourne, Australia

4. Centre for Disability and Development Research, Australian Catholic University, Melbourne, Australia

\section{Corresponding Author}

Professor C Imms ORCID ID: 0000-0001-9055-3554

Centre for Disability and Development Research, Australian Catholic University, 17 Young Street, Fitzroy, Melbourne, 3065, Australia; christine.imms@acu.edu.au

\section{Declaration of Interest}

All authors report no conflict of interest.

Word count: 6144

Tables: 1 Figures: 1 


\begin{abstract}
Purpose: To understand parents' experiences of evidence-based assessment by health professionals for their child with cerebral palsy.

Methods: A qualitative interpretive description study was undertaken. Primary carers of children with cerebral palsy (aged 3-18 years) from south-eastern Australia were invited to participate. Face-to-face interviews were held using a semi-structured topic guide and data analysed inductively. Credibility was ensured through: journal reflections; co-author review; audit trail; and, participant member-checking.
\end{abstract}

Results: Fourteen parents of children with cerebral palsy, representing Gross Motor Functional Classification System levels I-V, participated. Six themes emerged: (1) Protection; (2) Positively Framed; (3) Bridging the Gap; (4) Involvement; (5) Finding Worth; and (6) Trust. Central to parents' experience was protection of their child's identity and personal self. Assessment can be emotionally confronting, at any stage. Representing the child positively and highlighting possibilities was deemed essential. Parents' involvement ranged from being overlooked spectators to being instigators of assessment. Evidence-based assessment was worthwhile when relevant to parents' direction and family context. The researchers' interpretive description generated a schema and metaphor - the Steering Wheel for Collaborative Assessment.

Conclusions: A strengths-based approach to diagnosis and assessment is essential. The resulting interpretive description may assist health professionals align evidence-based assessment practices with family-centred care.

\title{
Keywords
}


parents; assessment; involvement; family-centred care; evidence-based practice; cerebral palsy

\section{Implications for rehabilitation}

- Parents of children who have cerebral palsy describe having to protect their child's identity and representation, and their own personal well-being, through evidencebased assessment and diagnostic processes.

- Involving parents in the process of evidence-based assessment and adopting a strengths-based approach is essential.

- The interpretive description developed - the Steering Wheel for Collaborative Assessment - may assist health professionals to implement evidence-based assessment tools in ways consistent with family-centred care principles. 


\section{Introduction}

The number and availability of psychometrically robust assessment tools has increased markedly in cerebral palsy research and practice $[1,2]$. Information from appropriately selected tools can guide allied health practitioners, children and families with goal setting, planning interventions, predicting resource needs and provide objective evaluation for interventions [3-5]. Assessment tools are defined as evidence-based when there are published instructions on how to administer, score and interpret the assessment, and acceptable levels of reliability and validity when used with the population of interest, in this case children with cerebral palsy [3]. Including psychometrically robust assessments (hence forth referred to as evidence-based assessment tools) in practice is widely advocated, as health professionals strive to strengthen their evidence-base for practice, and consumers and funders seek greater accountability from service providers [6,7]. The term 'evidence-based assessment' will be used in relation to the overall assessment process i.e. the procedures, actions and interactions involved with using evidence-based assessment tools. Evidence-based assessment is considered both the use of research to guide which assessment tool to use and an assessment process that integrates the use of psychometrically robust assessment tools, when available, with family preferences, and clinician expertise.

In the area of childhood disability, use of evidence-based assessment tools needs to be considered within the context of family-centred care [8,9]. An increasing body of research links family-centred care to enhanced parent well-being and optimal child outcomes [10,11]. Central to family-centred care is the emphasis on child and family strengths and the formation of collaborative interpersonal relationships between professionals, families and children $[8,9]$. Collaboration is underpinned by shared-decision making, trust and open 
communication [9]. Parents consistently highlight their desire for well delivered, specific information in relation to their child's care [12-14]. If used collaboratively, evidence-based assessment tools can potentially enhance parent participation in decision-making about their child's therapy. However, the implementation of collaborative therapy practices has been identified by allied health professionals and families as an area requiring improvement $[15,16]$.

The uptake of evidence-based assessment tools by health professionals (occupational therapists, physiotherapists and speech pathologists, referred to collectively as therapists) remains slow $[17,18]$ with interventions to increase use showing only modest success [19]. Uncertainty about parents' perceptions of formally administered assessments and potential impact on the parent-professional relationship has been identified as a "sticking point" by therapists [20-23]. Parent perspectives of specific evidence-based assessment tools are variable, with some assessment tools perceived more positively [24-27] than others $[18,28,29]$. Parents' mixed responses and therapists' uncertainty with using evidence-based assessment tools suggests further investigation is needed. Parental experiences may provide valuable insights into the slow uptake and use of evidence-based assessment tools within the paradigm of family-centred care. This study, therefore aimed to understand parents' experiences of evidence-based assessment practices by health professionals for their child with cerebral palsy.

\section{Methods}

\section{Study Design}

A qualitative approach using interpretive description [30] was chosen. Interpretive description assumes a constructivist view of knowledge where meaning is constructed 
through social interaction, experience and context [31]. The design of interpretive description generates understanding about the human experience in a way that is meaningfully applied to clinical practice. This research was approved by the Australian Catholic University Human Research Ethics Committee (2017-257E).

\section{Participants and recruitment}

Primary carers of children with cerebral palsy living in south-eastern Australia were invited to participate. Eligibility included: prior experience of formally administered evidence-based assessment tools with an occupational therapist, physiotherapist or speech pathologist; ability to communicate in English; and their child aged 3 to 18 years. A heterogeneous sample was sought according to child age, Gross Motor Function Classification System level [32], and geographical home location to encompass a broad range of child-family circumstances [33].

No set rules exist regarding parameters for sample size in qualitative research. Often 'code saturation'- the point at which no further novel information is being added to the data set - is used to justify ceasing recruitment i.e. the researcher has 'heard it all'. This study aimed for 'meaning saturation' with sufficient data gathered to 'understand it all' [34]. Sixteen to 24 interviews are recommended to achieve meaning saturation [34].

Participants were recruited between January and May 2018. interested, parents contacted the primary author directly or gave verbal consent for their contact details to be forwarded. Recruitment continued alongside preliminary analyses, until new data did not add further meaning or significantly change the interpretation [34].

\section{Data Collection}


Participants provided study consent on entry to an online questionnaire as part of data collection. The online questionnaire was used to collect parent and child information to provide contextual background to the interviews. Information gathered included parent age, income, education and geographical location, and child age, gender, functional classification abilities for mobility, hand function and communication, and therapy service history.

Parents' experiences of their child's assessment with health professionals using evidencebased assessment tools were explored through face-to-face interviews conducted with the primary researcher (an experienced paediatric physiotherapist) at a private location chosen by the parent. A topic guide (see supplementary file 1) developed by the research team, all of whom have experience in qualitative research, was employed: assessment was explained broadly and in the context of health care, with examples provided of evidence-based assessment tools that parents were likely to have encountered. Initially, parents reflected on their experiences of their child's assessment broadly and then were asked to consider, more specifically, their experiences when evidence-based assessment tools were used. Interviews lasted between 30 and 90 minutes and were audio-recorded and transcribed verbatim by a professional transcription service. Transcripts were cross-checked with the original audio files.

\section{Data Analysis}

Interview data were analysed inductively using an interpretive description approach [30]. Analysis was immersive and iterative with stages that included: familiarisation with audio, textual and post-interview summary data; initial coding of textual data into broad thematic patterns; and, repeated testing and questioning of labels and linkages between and across data elements to clarify and finalise thematic interpretations. 
Final synthesis involved looking for potential relationships across themes and subthemes. Personal and discipline-specific critique was provided towards the final conceptual understanding and structure, and it's relevance to practice. Iterations developed by one researcher (BOC) were reviewed for authenticity by the other researcher team members $(\mathrm{CI}$, CK, NS). The final interpretive description was considered in relation to, and then situated within, current theoretical frameworks.

The influence of the authors' personal and clinical perspectives and experiences during data analysis was recognised and acknowledged. A documented audit trail of decisions during concept development and a reflective journal, were kept by the primary author.

Interpretations were documented and questioned throughout data collection and analysis. All co-authors were involved through: regular discussion and critique of evolving thematic descriptions and their interpretations; and, cross-checking of coded textual data against themes and sub-themes with differences resolved through discussion. Finally, study participants were asked to consider the 'authenticity' of the findings, that is, whether or not themes and final conceptual description — the schema and metaphor - 'rang true' according to their experiences.

\section{Results}

Fourteen parents (all maternal carers) of children with cerebral palsy (child age 3-14 years) participated in the study (see table 1). Parents were aged 30-54 years; two were sole-carers and one spoke English as second language. Children's therapy service histories encompassed all sectors (early intervention, hospital, school, private practice, and community health) with all children having received therapy from two or more therapy disciplines in the past.

[Insert table 1 with caption here] 
Six themes emerged: Protection; Positively Framed; Bridging the Gap; Involvement; Finding Worth; and Trust. These main themes and their associated sub-themes are discussed in detail below and are illustrated in figure 1.

\section{Protection}

This central theme included the sub-themes Protecting my Child's Identity and Protecting the Self and was influenced strongly by the Legacy of Diagnosis sub-theme. All parents described feeling 'anxious' and some parents 'fearful' with assessments and reported their need to protect the essence of their child through the assessment process. For some parents these feelings "stemmed from" distressing diagnostic experiences that subsequently impacted parents' willingness to engage with therapists and assessment.

So, yeah, I was just terrified. From that [early hospital experience] - I was so reluctant to go near hospitals or doctors. Really, at the age of nine, this is the first time I've taken him, because I don't want to lose control again. Par.\#4

Parents recounted how assessments often failed to reflect and adequately represent all facets of their child. This generated a strong desire within parents to Protect their Child's Identity: an individual in their own right - not a child defined by assessment, disability or diagnosis. Parents felt "quite confronted" when their child was "reduced to a number. Parents talked about needing to separate assessment terminology, such as "she's a five" from their child "who loves going in a helicopter".

Parents described ways of Protecting one's Self emotionally during the assessment process. Evidence-based assessment triggered visceral emotions in some parents, such as feelings of sadness, and vulnerability in the lead up to, during and when receiving associated prognoses and reports afterwards. Some parents chose not to "put themselves through it" to circumvent 
"judgement" and "feeling like you're in the principal's office" or witnessing their child's "failure because they are low down" or "don't fit" the assessment criteria. The assessment process brought up issues for parents "that are always under the surface”. Parents drew on different mental strategies to help ameliorate feelings of "disappointment" such as focusing on things that were changeable, "never having high expectations", and "manning up to face these things".

I can't focus on what I can't change, I've just got to go with it. I've got to accept where he is and who he is and what he is, and that makes me a much better person and parent, and happier in myself. Par.\#9

\section{Positively Framed}

Providing a positive perspective throughout the assessment process was a strong theme. Assessment needed to: provide positive Representation of their child; highlight Possibilities (not deficits); and, Support parents emotionally and practically by highlighting strategies parents could implement to support their child's development.

It can make or break your whole attitude toward how you're going to approach it, yeah. So when that physio just said that one thing 'see how he opens his hands, he's not clenching really tightly, that's a good sign' ...I was like, “That's fine. I'll take it.” Par.\# 11

Negatively-framed assessment heightened Protection and undermined parents' optimism and motivation "to get up every day" and subsequently engage with assessment. Examples of this included negatively based language, pass-fail scoring, prognoses and reports highlighting deficits and limited possibilities, such as those used to secure resources. 
They just went, "Therefore, he will never, he will never, he will never." I get the impression that it's still a very common story. I don't know why they do that. If you just say, “We expect this, but we don't know," that leaves some room for possibility or anything. Par.\#4

\section{Bridging the Gap}

This theme, and associated sub-themes, illustrates parents' evolving understanding and feelings about evidence-based assessment. The Gap refers to the different perspectives of the child during the assessment process - the parent's intimate view and connection with their child's interactions and the therapist's analytical interpretation of the child's presentation. Parents recalled struggling initially to make sense of unfamiliar assessment practices - parents were Unknowing of what the assessments were, why they were being done, what the findings from assessments meant for them and their child, and the roles of different health professionals.

What therapists ascertain from those assessments is beyond me, you know. It's completely foreign. Par.\#5

Although many parents wanted to know "as much as possible in black and white" early on about their child and their future, parents also recounted their simultaneous desire for retaining some ambiguity.

I think if she had have done that test and said, "Oh, that's where he's going to get to; let's draw the line there", it would have been really, really disheartening, and really deflating, and really hard to deal with. Par.\#10 
Parents reported becoming more familiar with the assessment process and knowing "what's expected of us". Parents' initially Complied with therapists' requests for assessment rather than wanting to be formally assessed. For many parents, assessment remained linked with underlying feelings of disappointment, sadness and frustration. Some parents felt Resigned to the assessment process, deeming it necessary despite its perceived limitations. For other parents, the "scariest" early assessments were Reconciled and eventually appreciated, if perceived to be beneficial.

You do get used to some of the expectations, I guess, but, you know, it's generally, with clothes off, just in a nappy. And already, as a parent, you're ticking —no one wants their child naked. Par.\#5

\section{Involvement}

Parents described being involved with their child's assessment in a continuum of ways related to being; Overlooked, Spectators, Intermediaries, Mentees and Mentors, and Instigators of assessment. Often, involvement with assessment needed to be balanced with the Personal and Practical Costs of undertaking the assessment.

When Overlooked, parents felt disempowered: they recounted not being informed that assessments had taken place; feeling peripheral to conversations between professionals about their child's assessment; and either, not receiving assessment results, or receiving results that were "mentioned down the track" or as an "off-hand remark". Parents often felt overwhelmed by the amount and complexity of information, and consequently found it difficult to interpret and relate assessment information to their child, particularly when the terminology and acronyms carried little meaning. 
Ifeel superfluous to be honest. ...I'm just the one that dresses and appropriately points and holds and-yeah, I'm just the one-the 'staff member' that knows the baby best, so that is sort of it really. Par.\#5

Parents described being Spectators of assessments in two ways. When relegated, parents stood by as observers or kept out of the way; parents responded to therapists' questions but were not able to "volunteer" information easily, particularly in clinic environments that were "scheduled to the minute". Parents stepped back voluntarily during assessments with trusted practitioners as their child got older. This was an active choice by parents wanting more independent relationships to develop between their child and their therapist.

Parents performed multiple tasks as Intermediaries during assessments to enable therapists to gather information efficiently and accurately. Parents recounted "interpreting in both directions" between their child and the therapist and assisting with physical handling to ensure their child's comfort and safety. Parents recalled their difficulty "preparing my child" when insufficient information was provided about the assessment procedure beforehand. As children became older, parents increasingly needed to be able to "backup and reinforce" information about assessments with their child and adapt information for different family members and friends. To do this, they needed therapists to "keep it simple".

Some parents felt they were Mentees to therapists who helped to develop their understanding of assessments whereas other parents felt more support was needed. As mentees parents reported needing to "feel comfortable" asking questions and "owning a thirst" for information to support their child. Parents were also Mentors to therapists by providing support to novice practitioners in how to interact with their child and to listen and receive guidance from parents. Mentoring therapists was viewed as important not only for their child, but also to benefit other families. As parents became familiar with individual assessments and 
how they were used, they reported being less reliant on therapists' and more proactive Instigators of relevant evidence-based assessment for their child.

Parents' described how involvement with assessment-related appointments significantly drew on practical, financial, family and emotional resources, and their time for usual parenting activities. Parents needed access to reliable transport, care for siblings, and flexible work options. Mothers' reported their partners were rarely able to attend assessments, leaving them to "hold information" and deal with the emotional impacts of assessment alone. Parents also described the burden of assessment on their child. While some assessments were fun and viewed as a "special time", others were long and draining (for both child and parent) and sometimes physically uncomfortable.

So, trying to get Jess to fully bend her knee and actually measure the angle. She didn't like that so much. I mean, she's very, very tolerant of pain and you know, she's so used to people doing these sorts of things to her, or with? - no, maybe 'to her'. She looked visibly uncomfortable. .... She doesn't hold a grudge even though they just straightened her leg out and I didn't want them to. Par.\#2

\section{Finding Worth}

This theme captured what made assessment worthwhile for parents and related to tool Accessibility; An Eye on Things; New Insights; Making Plans; and, Relevant and Helpful. Worth changed as a parent's Focus changed for their child.

Parents recounted variable Access to assessments in the early years and that there was "nothing really helpful" as their child got older. Parents also reported that priority assessments for younger children (e.g. range of movement) became less important over time, as their child's interests and social opportunities took precedence. Parents expressed concerns 
that this Change in Focus could result in physical deterioration, but this needed to be reconciled as part of the "constant juggle" for parents "between acceptance and cure".

It probably doesn't quite mean as much, because-you know, the first ten years, we're trying to always get better, get better, get better, what can we get out of him?

Whereas, you get to a certain point where you know —not that you accept, "Okay, this is how he is going to be," but recently we have kind of made a call. Par.\#9

High value, particularly in the early years, was placed on feedback from evidence-based assessments about their child's development. Parents described vividly their intense joy and motivation from positive Insights gained during assessment and felt reassured when their child' progress was being monitored by therapists who kept an Eye on Things and detected issues early.

I loved that, I loved to see that he was going to go up [on the Gross Motor Function Measure], even if it was a little bit. Every little bit gives hope to parents, and every little bit is positive. Par.\#9

Assessment was accepted as necessary for Making Plans and setting goals although some parents felt goals were "very limiting" and preferred to just stay "open to further improvement". Goal setting was described as unhelpful and disheartening if unrealistic, not revisited, or when outcomes were unusable in day-to-day settings. Parents understood goals were individualized to their child, however rating goal satisfaction "was tricky" as parents contemplated the disparity between how things are and how things could be "if able to do it all on his own ". Parents questioned the expectation by some therapists for parents to set goals without first having detailed assessment information. 
They always ask me, "so what would you like to achieve?" and I don't know. Normal life. How do we, you know normal life? I'm suddenly sweating there and like, I need to set a goal now. Oh, um, ah, I want him to ride a bike? Par.\#3

Parents described evidence-based assessment as (ir)Relevant and (un)Helpful when showing little or no positive change and no options existed to address the issue: parents didn't "need to be reminded he's not going anywhere". The process was Worth It when the assessment: had "a clear purpose"; was aligned with parents' focus and priorities; was "agreeable" to their child and themselves; and led to interventions that the "family can work with".

\section{Trust}

Experiences of evidence-based assessment were shaped by parents' relationship with therapists. This was articulated as Trust related to: Will it work?; Familiarity; Openness; and being In Good Hands. Many parents' viewed assessment as "for the therapist" and preferred the assessment process to be the therapists" remit so they could "be a Mum". Some parents recounted they "just did them" and took therapists "at their word" while other parents reported feeling they were "overstepping" if they asked therapists for assessment information. Others were surprised the assessment process could be shared thereby giving rise to the subtheme Assessment for Whom? Parents talked about needing to feel confident in the therapeutic relationship and described an initial period of determining Will It Work? Trust was difficult to establish when therapists were not able to adapt assessment and therapy approaches to parents' therapy ethos.

I was really coming from, "We're going to change." And she was really coming from, "It's inevitable... We're just going to work around and support" And I believe she would have created a disability. Par.\#4 
Parents emphasised it was easier when the assessment process was familiar - that is, knowing where and what was likely to happen - and therapists helped to reduce "the anxiety that builds" for the child. Parents' trust in assessment and the parent-therapist relationship was deeply undermined when therapists did not articulate their thoughts openly and parents' felt "left out in the dark" and were "the last to know". Parents sensed therapists' awkwardness and reluctance in "bringing it up" and sharing assessment information. While parents acknowledged this information was difficult to hear, parents in this study wanted Openness with therapists when discussing assessment information.

I just asked her, "Could I get a copy of that [AIMS assessment]?” And like, you know, it wasn't a secret or anything like that; it wasn't something that I wasn't allowed to have, but I just felt... It wasn't something that she was doing with me to then hand over. Par.\#10

Parents talked about their relief when feeling “in good hands”. Parents equated being In Good Hands when: therapists were practically and emotionally competent, had a good understanding of child development, and helped set realistic goals; support and guidance was provided when needed; and, parent and therapist expertise was freely exchanged.

\section{[Insert figure 1 about here]}

\section{Synthesis}

Synthesis of the six themes resulted in the interpretive description - the Steering Wheel for Collaborative Assessment. This schema and metaphor illustrate our understanding of parents' experiences of formal assessment. The Steering Wheel for Collaborative Assessment is characterised by a central hub with four radiating spokes to an outer rim. The hub contains two themes: Protection and a Positively Framed. Most central is Protection where parents act 
to protect: their child's being, representation and identity; and their own psychological wellbeing, during the assessment process. Positively Framed wraps around Protection and is connected by a dotted 'porous' line to indicate the potential dynamic influence of assessment on parents' need to protect. We propose how assessment, diagnosis and prognosis is implemented and framed strongly influence parents need to protect, with enduring impacts on collaboration and capacity building with parents.

The rim contains four themes: Bridging the Gap; Involvement; Finding Worth; and, Trust. Themes interact around the rim and individually with the central hub via a series of subthemes in the wheel segment connecting the hub to the rim and a generic sub-theme in the spoke sitting clockwise to the segment. The sub-themes in each segment are a continuum, where those closest to the hub describe less empowering and collaborative assessment experiences than those closer to the rim.

A parent's need to protect is magnified by negative assessment interactions, that: focus on deficits; speculate about what may not be possible; threaten child identity and representation; and, revive feelings of grief and erode optimism, making collaboration during assessment difficult. In these instances, the 'gap' between the parent and therapist view of assessment may widen. Parents may avoid evidence-based assessment interactions altogether or feel they can only participate as a resigned spectator of their child's assessment. Consequently, evidence-based assessment may hold little worth and decrease parent motivation to implement associated recommendations.

In contrast, positive assessment interactions, that identify and frame assessment and prognostic results in terms of possibilities, and focus on a child's strengths and identity, reduce parents need to protect; thereby enabling parents to be involved in assessment. When framed positively, parents may reconcile the limitations of available assessments, and feel 
able to choose how, and if, they want to be involved according to their circumstances, and priorities. Parents' assessment capacity can develop, enabling parents to instigate assessment that informs therapy relevant to the family's preferences. Assessment in this instance is underpinned by a collaborative therapeutic partnership that builds parent (and therapist) capacity, as represented beyond the rim.

The interactions in the Steering Wheel for Collaborative Assessment can be interpreted through two theoretical frameworks: the capacity-building paradigm [36] and parent selfefficacy [37].The capacity-building paradigm (unlike the traditional paradigm of professioncentered and deficit-based models) emphasizes family-centred, strengths-based and empowerment models [36]. Therapists act as agents to address parent priorities and concerns in ways that enhance competence and existing strengths. Positively Framed and Trust are consistent with the relational aspects of capacity-building that involve active listening, empathy and respect and positive beliefs about strengths and capabilities [36]. Similarly, themes of Involvement, Bridging the Gap and Finding Worth sit consistently with the participatory aspects of capacity-building practice that is individualised and responsive to family priorities and actively involves parents in making informed choices about their child's care [36]. Parental self-efficacy is linked positively with parental competence and improved mental health for both parent and child $[10,38,39]$. The Steering Wheel for Collaborative Assessment describes parents' assessment experiences as positive and empowering but also confronting and dis-empowering. These negative assessment experiences may have implications for parent self-efficacy and child well-being and raises questions about how evidence-based assessment is implemented in practice.

The Steering Wheel for Collaborative Assessment also provides a metaphor for assessment: by illustrating parent experiences of assessment in a Steering Wheel schematic, we align the 
assessment process with driving, with choices required about whether to and when to drive, where to go, and the route to be taken. Assessment determines the directions for therapy interventions - a process driven traditionally by the therapist or rehabilitation team. Within the paradigm of capacity-building one can ask who is holding the wheel and how tightly - the therapist, the parent and child, or, both?

Assessment is a learning process for parents and their child that may require therapists to loosen their grip on the wheel if wanting parents to come on board. By viewing themselves as a co-driver, therapists might hold the steering wheel initially but then move across into the passenger seat, so the parent can hold the wheel. The therapist can guide the parent through the assessment options and process, touching the wheel when needed and discussing how assessment information can be used to plan the route and steer towards the parent and child's destination. With time and experience, parents may hold the wheel, requesting more, or less, navigation support as needed. When the decision-making terrain becomes complex parents may prefer their co-driver to hold the wheel. When parents feel the need to protect their child's identity or themselves, they can 'honk the horn'. Co-drivers come and go in children's lives, so within this capacity-building paradigm for assessment, parents and children are better placed to hold the wheel and navigate the next trip with a new co-driver.

\section{Participant member-checking responses}

Ten parents provided their impressions on how and whether the themes, sub-themes and descriptors, and Steering Wheel schema, related to their experience of evidence-based assessment. The themes and Steering Wheel schema were received positively by all respondents. All parents reported they could see themselves somewhere in the Steering Wheel either in all, or, in some themes. Where parents did not relate to a theme personally, 
parents were able to relate the theme to the experiences of parents they knew. One parent identified she could see where she was on the Steering Wheel and where she had been.

I have read the study findings and I can honestly say that it all rings true - in all areas of the steering wheel. It either captures our own personal experiences or my feelings toward the process. Nothing in these findings is awkward or uncomfortable - just very relevant. Par.\#11

Some of the information rings true for us and some doesn't, however the parts that don't match our scenario, I have definitely heard through other families telling their stories. Par.\#10

Following discussion with participant Par.\#1 the co-driver metaphor was extended to describe how therapists working collaboratively were able to share the Steering Wheel in reponse to parents' capacity to manage the assessment process at different stages and times in their lives. The original theme of Mentor was also extended to Mentor-Mentee to reflect learning as bi-directional between parents and therapists in relation to the assessment of their child - a concept that was present in the data but not linked thematically.

\section{Discussion}

The findings from this study highlight the practical and emotional complexities posed by evidence-based assessment for some parents and demonstrate that these complexities do not necessarily abate with time. The six themes: Protection; Positively Framed; Bridging the Gap; Involvement; Finding Worth; and Trust provide insight into how evidence-based assessment tools are experienced by parents. The final interpretive description we developed — the Steering Wheel for Collaborative Assessment—may help guide more familycentred evidence-based assessment. Our findings are consistent with previous reports 
indicating parental discomfort associated with the use of specific evidence-based assessment tools $[18,28,29]$. By exploring parents' experiences of evidence-based assessment more broadly further insights have been gained as to why some parents may find the assessment process for their child persistently challenging. Reasons suggested by this study relate to: the way assessments are used with parents; how the child is represented through assessment; and, the assessment process itself as a possible trigger of grief symptoms for some parents.

This study highlights an aspect of assessment that has not been widely explored in the paediatric literature $[27,40]$. The experience of grief for some parents of children with disabilities can be cyclic with grieving symptoms revived by specific triggers that expose a disparity between "what could have been or was imagined" with "what is". The term chronic sorrow $[41,42]$ has been used to describe this recurring and ongoing grieving process for parents where symptoms can be triggered by smaller "loss events" [43]. Our study suggests that evidence-based assessment may trigger a "loss event" for some parents, with symptoms experienced in the lead up to, during and after an assessment encounter. This may explain in part why some parents may find assessment confronting at any time and feel resigned to, rather than engaged with, evidence-based assessment as a routine part of therapy. If, as suggested, evidence-based assessment has the potential to disturb parent well-being and parent-child interactions, we suggest the use of evidence-based assessment tools is not a benign activity. Using an evidence-based assessment tool should be viewed as an intervention requiring risks of harm be managed accordingly.

Parents desired and valued specific assessment information in many instances but also acknowledged the emotional challenge of receiving assessment information when progress and prognoses were less than expected or hoped for. Therapists have previously recounted their unease with discussing assessment results [20,23] and reported concerns about the 
potential negative impact on the parent-therapist relationship [21]. Parents in our study sensed therapists' apprehension and avoidance with discussing less favourable assessment information. It has been proposed that therapists may relieve their professional responsibility when discussing potentially challenging information to preserve this parent-professional relationship [21]. Nonetheless, therapists' have a duty of care to provide evidence-based information, so parents can make evidence-informed decisions about their child's care. This raises an important issue for health professionals, parents, service providers, educators and researchers - how to implement evidence-based assessment without inducing parent stress or causing harm?

It was concerning that some parents reported feeling and being excluded from the assessment process for their child. Given the personal and practical cost of assessment, and the pivotal role parents performed as Intermediaries, it is crucial parents gain as much as possible from the assessment process. Dis-empowering parents in the decision-making process can lead to parents feeling heightened levels of sole responsibility and increased levels of stress $[15,44]$. Increasing meaningful participation in the assessment process may reduce parental stress with potential benefits for parent-child interactions and child health literacy. Evidence-based assessment can thus be a therapeutic intervention in itself.

This study revealed a harmful legacy for parent mental health and subsequent engagement with therapy when a child's initial diagnosis and early assessment was negatively framed. Careful thought needs to be given to how the language of assessments, diagnosis and prognosis is framed and its implications for parents and children with lifelong disabilities [45]. This study suggests health practitioners may not always be cognisant of the need to shift language and assessment terminology in ways that fully respect and reflect the promotion of child development, identity and belonging for all. Skill development in how to implement 
evidence-based assessment with parents from a strengths-based perspective is needed to ensure parent self-efficacy, parent-child intimacy and optimism are preserved.

\section{Limitations}

The design of this study has enabled a thorough exploration of the experiences of a small group of primary carers from rural, regional and metropolitan settings of Australia with children represented across all Gross Motor Function Classification System levels.

Recruitment strategies used in this study naturally biased results towards participants willing and able to share their stories. The views expressed are representative of a small number of parents and, as is the case with many qualitative studies, cannot necessarily be generalised beyond this parent group and context. However, the insights provided may be considered more broadly when working with parents of children with childhood onset disabilities and offer initial data on an important area for further enquiry. The clinical expertise within the research team added strength to the interpretive description [46]. Additional data sources, however, may have further enhanced the trustworthiness of the findings.

\section{Implications}

The Steering Wheel for Collaborative Assessment provides a potentially useful platform for health professionals, parents, educators, researchers and tool developers to reflect on how formal evidence-based assessment tools are used with families and to support more participatory assessment practices. Therapists and parents might consider: where their experiences of assessment sit in the Steering Wheel; future aspirations and related assessment choices; the Steering Wheel as a useful starting point for navigating 'difficult' conversations that acknowledges the experience of assessment for parents and Bridges the Gap. 
The findings also have relevance to student and professional education. Training in the use of evidence-based assessment tools often occurs in de-contextualised learning environments (e.g. university). The primary focus of training is often to achieve competency and reliability with assessment administration and scoring. Limited focus is provided on how to positively frame and involve parents and children in the assessment process. Thus, when implementing new assessments in practice, therapists and students may be unsure how to navigate parenttherapist interactions when implementing and discussing assessment results. Therapists may choose not to implement the assessment or avoid difficult conversations, both of which undermine good practice and can potentially do harm.

Within the research context, evidence-based assessment tools are used to address the research question rather than guide the therapy needs of an individual child and family. As potential study participants, parents weigh up the cost for themselves and their child. Families may volunteer in anticipation of possible benefits for their own child or other children in the future. Research assessment results however may not be shared with individual participants, and if provided, may not be scaffolded positively with individualised support. It is not known how evidence-based assessment tools conducted within research impact parents and children and their participation in future research projects.

For tool developers, the findings strongly support involving parents and children in the conceptual stage of development to clarify purpose, ensure acceptability and develop guidelines for collaborative administration. Traditional criteria to assess clinical utility of assessment tools seem insufficient to capture the subjective experience of specific assessment tools for parents and children. A precedent in this direction has been set by the developers of the Challenge assessment tool. Child and caregiver experiences of the Challenge were 
integrated with family-centred care principles to develop specific guidelines for collaborative assessment [27] when using the tool.

Further research to understand the assessment experiences of other parent groups, and importantly children, is needed. Further exploration of parent-professional assessment interactions and Steering Wheel concepts in practice is warranted to facilitate family-centred evidence-based assessment.

\section{Conclusions}

This study has highlighted parents experience of evidence-based assessment is not benign. Evidence-based assessment can be experienced positively, but concerningly, can also induce parent feelings of needing to Protect their child's identity and own psychological well-being. The parent perspective can be appreciated clinically through the interpretive description of the thematic findings - the Steering Wheel for Collaborative Assessment. Recognition of the central concepts of Protection and Positively Framed may help Bridge the Gap between parent-professional perspectives during assessment. Involvement and Finding Worth highlight ingredients that may support (or undermine) parents' Trust and participation and thereby influence collaboration during assessment. While further work is needed, metaphorically the Steering Wheel allows parents and health professionals to reflect on why we are assessing, where are we going, who is holding the assessment wheel and if there a willingness to share the driving.

\section{Acknowledgements}

We sincerely thank the parents who willingly provided their time and trust to share their personal reflections and stories for this study to benefit others. The authors also appreciate the assistance from Paula O'Hagan with graphic design and Joan Gains and Vicki Cavalieros 
with recruitment, and the generosity of individual therapists and staff from organisations, who cannot be listed here to protect confidentiality of the participants.

\section{Disclosure statement}

All authors report no conflict of interest

\section{Funding}

Financial support for transcription costs was provided through the FRSSS fund Australian Catholic University, Melbourne Australia. No other financial support was received in the authorship or publication.

\section{References}

[1] Wu YW, Mehravari AS, Numis AL, et al. Cerebral palsy research funding from the national institutes of health, 2001 to 2013. Dev Med Child Neurol. 2015;57:936-941.

[2] Schiariti V, Fowler E, Brandenburg JE, et al. A common data language for clinical research studies: The national institute of neurological disorders and stroke and american academy for cerebral palsy and developmental medicine cerebral palsy common data elements version 1.0 recommendations. Dev Med Child Neurol. 2018;60:976-986.

[3] Wright FV, Majnemer A. The concept of a toolbox of outcome measures for children with cerebral palsy: Why, what, and how to use? J Child Neurol. 2014;29:1055-1065.

[4] Bartlett DJ, McCoy SW, Chiarello LA, et al. A collaborative approach to decision making through developmental monitoring to provide individualized services for children with cerebral palsy. Phys Ther. 2018;98:865-875.

[5] Palisano RJ. A collaborative model of service delivery for children with movement disorders: A framework for evidence-based decision making. Phys Ther. 2006;86:1295-1305.

[6] Ketelaar M, Russell DJ, Gorter JW. The challenge of moving evidence-based measures into clinical practice: Lessons in knowledge translation. Phys Occup Ther Pediatr. 2008;28:191-206.

[7] Unsworth CA. Evidence-based practice depends on the routine use of outcome measures. Br J Occup Ther. 2011;74:209-209. 
[8] King G, Chiarello L. Family-centered care for children with cerebral palsy:Conceptual and practical considerations to advance care and practice. J Child Neurol. 2014;29:1046-1054.

[9] Kuo DZ, Houtrow AJ, Arango P, et al. Family-centered care: Current applications and future directions in pediatric health care. Matern.Child Health J. 2012;16:297-305.

[10] Dunst CJ, Trivette CM. Meta-analytic structural equation modeling of the influences of family-centered care on parent and child psychological health. Int J Pediatr. 2009;2009:576840

[11] Järvikoski A, Härkäpää K, Martin M, et al. Service characteristics as predictors of parents' perceptions of child rehabilitation outcomes. J Child Health Care. 2015;19:106-117.

[12] Kruijsen-Terpstra AJ, Verschuren O, Ketelaar M, et al. Parents' experiences and needs regarding physical and occupational therapy for their young children with cerebral palsy. Res Dev Disabil. 2016;53:314-322.

[13] Jackson C, Cheater FM, Reid I. A systematic review of decision support needs of parents making child health decisions. Health Expect. 2008;11:232-251.

[14] Resch JA, Mireles G, Benz MR, et al. Giving parents a voice: A qualitative study of the challenges experienced by parents of children with disabilities. Rehabil Psychol. 2010;55:139.

[15] Dempsey I, Keen D, Pennell D, et al. Parent stress, parenting competence and familycentered support to young children with an intellectual or developmental disability. Res Dev Disabil. 2009;30:558-566.

[16] An M, Palisano RJ, Yi Chung-hwi, et al. Effects of a collaborative intervention process on parent-therapist interaction: A randomized controlled trial. Phys Occup Ther Pediatr. 2018:1-17.

[17] O'Connor B, Kerr C, Shields N, et al. A systematic review of evidence-based assessment practices by allied health practitioners for children with cerebral palsy. Dev Med Child Neurol. 2016;58:332-347.

[18] Bailes AF, Gannotti M, Bellows DM, et al. Caregiver knowledge and preferences for gross motor function information in cerebral palsy. Dev Med Child Neurol. 2018;60:1264-1270.

[19] Colquhoun H, Lamontagne ME, Duncan EA, et al. A systematic review of interventions to increase the use of standardized outcome measures by rehabilitation professionals. Clin Rehabil. 2016;April 18:10.

[20] Krohne KT, Sandra; Sletteb $\varnothing$, Åshild; Bergland, Astrid. Individualizing standardized tests: Physiotherapists' and occupational therapists' test practices in a geriatric setting. Qual Health Res. 2013;23:1168-1178. 
[21] Reeder J, Morris J. The importance of the therapeutic relationship when providing information to parents of children with long-term disabilities: The views and experiences of uk paediatric therapists. J Child Health Care. 2018;22:371-381.

[22] King G, Wright V, Russell DJ. Understanding paediatric rehabilitation therapists' lack of use of outcome measures. Disabil Rehabil. 2011;33:2662-2671.

[23] O'Connor B, Kerr C, Shields N, et al. Understanding allied health practitioners' use of evidence-based assessments for children with cerebral palsy: A mixed methods study. Disabil Rehabil. 2017:1-13.

[24] Öhrvall AE, A. Parents' and therapists' perceptions of the content of the manual ability classification system, macs. Scand J Occup Ther. 2010;17:209-216.

[25] Kerr C, Imms C, Foley S, et al. Parent perceptions of routine clinical assessment for children with cerebral palsy. (abstract) Physiotherapy. 2016;102:e243-e243.

[26] Øien I, Fallang B, Østensjø S. Goal-setting in paediatric rehabilitation: Perceptions of parents and professional. Child Care Health Dev. 2010;36:558-565.

[27] Gibson BE, Mistry B, Wright FV. Development of child and family-centered engagement guidelines for clinical administration of the challenge to measure advanced gross motor skills: A qualitative study. Phys Occup Ther Pediatr. 2017:110.

[28] Rich D, Rigby P, Wright V. Mothers' experiences with the pediatric evaluation of disability inventory (pedi). Phys Occup Ther Pediatr. 2014;34:271-288.

[29] Scime NV, Bartlett DJ, Brunton LK, et al. Parents' experiences and perceptions when classifying their children with cerebral palsy: Recommendations for service providers. Phys Occup Ther Pediatr. 2017;37:252-267.

[30] Thorne SE. Interpretive description. Walnut Creek, CA: Left Coast Press; 2008.

[31] Crotty M. The foundations of social research: Meaning and perspective in the research process. St Leonards, Australia: Allen \& Unwin; 1998.

[32] Palisano R RP, Walter S, Russell D, Wood E, Galuppi B. Development and reliability of a system to classify gross motor function in children with cerebral palsy. Dev Med Child Neurol. 1997:214-223.

[33] Liamputtong P. Qualitative research methods. 4th ed. South Melbourne: Oxford University Press; 2013.

[34] Hennink MM, Kaiser BN, Marconi VC. Code saturation versus meaning saturation: How many interviews are enough? Qual Health Res. 2017;27:591-608.

[35] Pryse GS. Mothers _Vote labour. [artwork] Courtesy of People's History Museum; Manchester (UK) c.1919 
[36] Dunst CJ, Trivette CM. Capacity-building family-systems intervention practices. J Fam Soc Work. 2009;12:119-143.

[37] Bandura A. Self-efficacy: Toward a unifying theory of behavioral change. Psychol Rev. 1977;84:191-215.

[38] Jones TL, Prinz RJ. Potential roles of parental self-efficacy in parent and child adjustment: A review. Clin Psychol Rev. 2005;25:341-363.

[39] Trivette CM, Dunst CJ, Hamby DW. Influences of family- systems intervention practices on parent-child interactions and child development. Top Early Child Special Educ. 2010;30:3-19.

[40] Bjorbaekmo WSE, Gunn H. Experiences of being tested: A critical discussion of the knowledge involved and produced in the practice of testing in children's rehabilitation. Med Health Care Philos. 2011;14:123-131.

[41] Olshansky S. Chronic sorrow: A response to having a mentally defective child. Soc Casework. 1962;43:190-193.

[42] Phillips M. Chronic sorrow in mothers of chronically ill and disabled children. Issues Compr Pediatr Nurs. 1991;14:111-120.

[43] Hobdell E. Chronic sorrow and depression in parents of children with neural tube defects. J Neurosci Nurs. 2004;36:82-88,94.

[44] Knox M. Family control: The views of families who have a child with an intellectual disability. J Appl Res Intellect Disabil. 2000;13:17-28.

[45] Svendby RR, Grace Inga; Moen, Kåre. The language of percentages: Ranking bodies, shaping realities, and limiting opportunities. Disabil Rehabil. 2017:1-7.

[46] Hunt MR. Strengths and challenges in the use of interpretive description: Reflections arising from a study of the moral experience of health professionals in humanitarian work. Qual Health Res. 2009;19:1284-1292. 
table 1: Parent and child characteristics.

\begin{tabular}{llllcccc} 
Parent & & Child & \multicolumn{3}{c}{ Functional Classification* } \\
\hline Code & Education & $\begin{array}{l}\text { Home } \\
\text { location }\end{array}$ & $\begin{array}{l}\text { Gender } \\
\text { female (F) } \\
\text { male (M) }\end{array}$ & $\begin{array}{l}\text { Age } \\
\text { (years) }\end{array}$ & $\begin{array}{l}\text { GMFCS } \\
\text { (level) }\end{array}$ & $\begin{array}{l}\text { MACS } \\
\text { (level) }\end{array}$ & $\begin{array}{c}\text { CFCS } \\
\text { (level) }\end{array}$ \\
\hline Parent \#1 & Postgraduate & Metropolitan & F & 14 & II & II & II \\
Parent \#2 & Degree & Metropolitan & F & 14 & V & IV & III \\
Parent \#3 & Year 12 & Metropolitan & M & 8 & II & II & III \\
Parent \#4 & Certificate & Rural & M & 8 & II & II & III \\
Parent \#5 & Certificate & Regional & M & 3 & IV & IV & IV \\
Parent \#6 & Year 12 & Rural & F & 12 & II & II & I \\
Parent \#7 & Certificate & Regional & F & 14 & I & III & III \\
Parent \#8 & Certificate & Regional & F & 6 & V & V & V \\
Parent \#9 & Postgraduate & Rural & M & 12 & III & I & I \\
Parent \#10 & Postgraduate & Regional & M & 3 & V & V & IV \\
Parent \#11 & Degree & Metropolitan & M & 11 & III & II & I \\
Parent \#12 & Postgraduate & Metropolitan & M & 11 & III & III & I \\
Parent \#13 & Certificate & Regional & F & 7 & I & II & I \\
Parent \#14 & Certificate & Regional & F & 10 & I & III & III \\
\hline ?
\end{tabular}

"Classification legend; Gross Motor Function Classification System; MACS, Manual Abilities Classification System;CFCS, Communication Function Classification System 
figure 1: The Steering Wheel for Collaborative Assessment. Themes of Protection and Positively Framed sit in the central hub. The porous line between Protection and Positively Framed denotes the dynamic interaction between formal assessment and parents' need to protect: Protection recedes or expands in response to whether assessment is framed positively or negatively, which consequently impacts on possibilities, support and representation. The central themes in the hub influence the four themes located on the rim of the Steering Wheel: Bridging the Gap; Involvement; Finding Worth; Trust. Sub-themes for each of the rim themes are detailed in the segment connecting the hub to the rim, with more collaborative experiences denoted by closer proximity to the rim. Additional sub-themes, related to those presented in each segment, are presented in the spoke located clockwise to the relevant segment. Central image: Courtesy of People's History Museum [35].

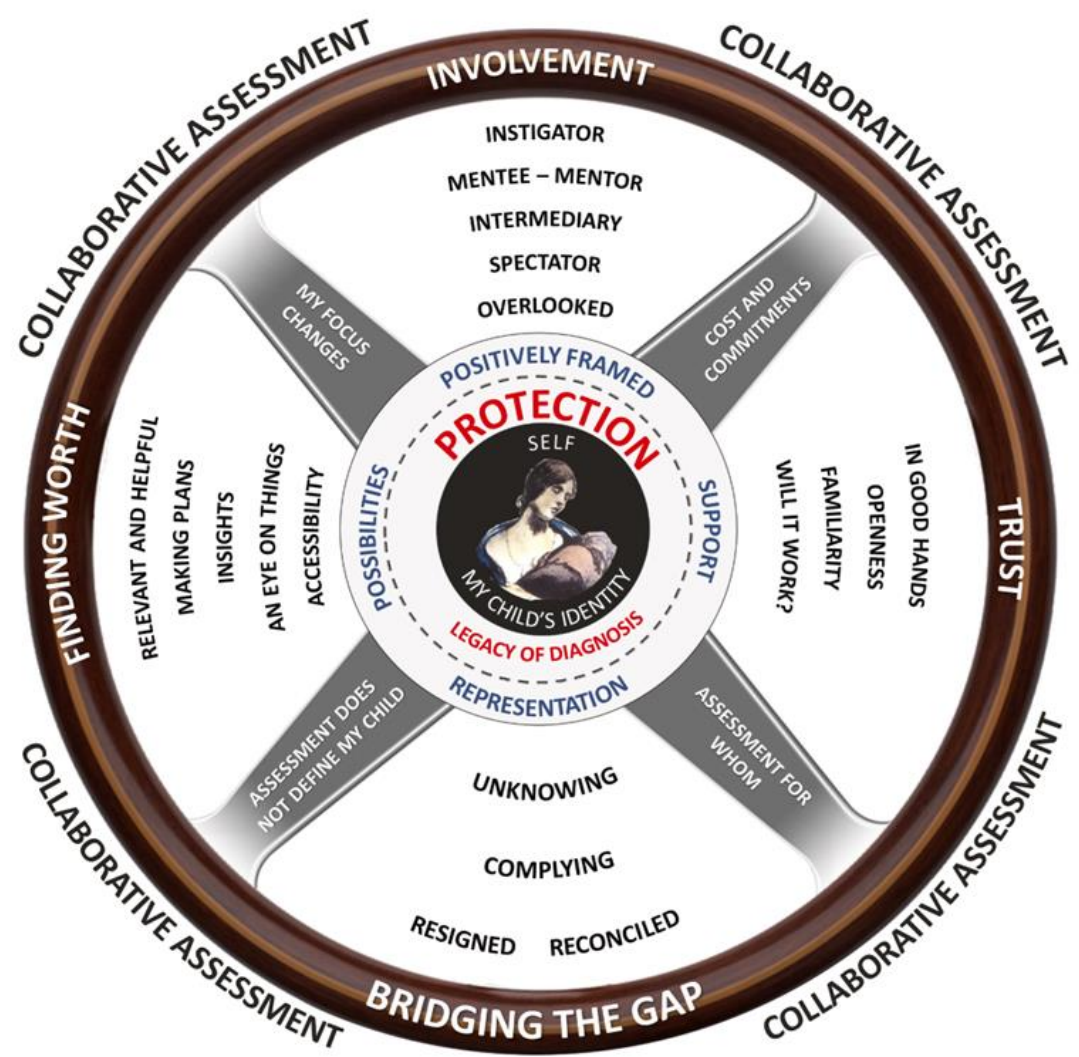


25 March 2019

To whom it may concern,

People's History Museum hereby grants non-exclusive reproduction rights to Bridget O'Connor for the below images to be incorporated into the research manuscript 'Steering towards collaborative assessment: A qualitative study of parents' experiences of evidence-based assessment for their child with cerebral palsy' for publication in the joumal Disability and Rehabilitation and Ms O'Connor's published $\mathrm{PhD}$ thesis.

Permission is also granted for the inclusion of the image in the book Participation in Childhood Disabilities to be published by Mac Keith Press. The copyright and ownership rights in all images supplied by the Museum and any derivative images produced will remain with the Museum

\section{The images:}

1995.35.8 - Labour Party Poster, 'Mothers Vote Labour'

There will be a total fee of $£ 150+$ VAT for the inclusion of the image in both journal and book.

Please could you ensure that the following credit line is used:

"Courtesy of People's History Museum"

Yours Sincerely,

Sam Jenkins

Collections Officer 
Supplementary file 1: topic guide

\section{Interview Topic Guide}

\section{Thank you and house keeping}

Just to remind you that I will be recording todays interview but your and other names will be deidentified and that our discussion today will remain confidential. Do you have you any questions regarding this? Audio started.

\section{Background introduction to assessment}

The topic we are talking about today is assessment and I'm interested in your experiences of assessment with therapists (OTs, PTs and SPS) that you have been involved with up until now.

When talking about assessment, I mean the way we gather and use information to help make judgments and decisions about things like therapy goals, therapy programmes or services for (name), or to monitor (name)'s progress with a therapy programme or goals related to aspects of (name)'s mobility, self-care, behaviour, social skills and communication.

Typically, therapists would collect this information through; discussion with you and your child; observing him/her in different settings; but also by using more formal methods such as specific tests, measures or scales. Some common examples of these tests would include things like; goniometry to measure joint movement, or a walking assessment that's been timed or videoed, or where your child is asked to do a series of set tasks and a score sheet is used to record his/her performance e.g. Gross Motor Function Measure (GMFM), Assisting Hand Assessment (AHA), or a language assessment, or you might be asked to fill out responses to a list of questions e.g. Pediatric Evaluation of Disability Inventory (PEDI), or prioritise goals using numbers e.g. Canadian Occupational Performance Measure (COPM) or Goal Attainment Scaling (GAS).

\section{Before we start talking about assessment specifically, can you tell me a bit about your child?}

How is a typical day for your child?

What sorts of things does your child like doing?

Where's s/he up to with school?

2. The topic we are talking about today is assessment and I'm interested in your experiences of assessment with physiotherapists, occupational therapists and speech pathologists that you have been involved with up until now.

Can you tell me about what comes to mind when you reflect on your experiences of assessment with [child's name]?

Probes:

$\square$ How do you find assessment generally?

Who is involved? What happens?

How is it for [child's name]?

3. I would like to go on and talk more specifically now about your experiences of formal sorts of assessment that are used with observations and discussion such as specific tests, measures and scales. Can you think back and describe for me your experiences of a formal assessment with (child's name) perhaps the last time or another time that you can remember?

Probes: Can you tell me about... 
What happened? Where did it happen? Who was there?

How did the assessment come about?

In what ways were you involved in the assessment for [child's name]?

What did you hope to get from the assessment?

Can you tell me about how the assessment process was for you, as the parent?

- What went well?

○ What didn't go well (if anything)?

$\square$ How do you think [child's name] found the assessment, or finds assessments generally?

How was the information from the assessment used? Explore relationship to goal setting

What did you (or your child) get from the assessment?

How did you feel about this information?

What did you do with this assessment information?

Who else was able to use the information?

How important is it to you that your child receives formal assessment?

How do you think your child's therapists value assessments?

How would you prefer to be involved in formal assessments for your child? Why?

\section{Wrapping $U p$}

We have talked in detail about a very specific assessment experience, is there anything else you'd like to share with me about you and your child's assessment experiences? 